\title{
Regulation of Human Jejunal Glycolytic Enzymes by Oral Folic Acid
}

\author{
Norton S. Rosensweig, Robert H. Herman, Fred B. Stifel, and \\ YAYE F. HeRMaN \\ From the Metabolic Division, U. S. Army Medical Research and Nutrition \\ Laboratory, Fitzsimons General Hospital, Denver, Colorado 80240
}

A в S T R A C T The effect of oral folic acid on jejunal glycolytic enzyme activity in five fasting obese patients and in three normal male volunteers on a constant 3000 cal diet was studied. The glycolytic enzymes, fructokinase, hexokinase, glucokinase, fructose-1-phosphate aldolase, and fructose diphosphate aldolase, and the disaccharidases, sucrase, maltase, and lactase were measured.

In both the fasting patients and the normal volunteers, oral folic acid significantly increased the jejunal glycolytic enzyme activities but had no effect on disaccharidase activity. When oral folic acid was discontinued in the normal volunteers, the glycolytic enzyme activities returned to control values. In the obese patients, refeeding and folic acid caused a further increase in glycolytic enzyme activities above that seen with fasting and folic acid.

In contrast to oral folic acid, intramuscular folic acid, oral vitamin $B_{12}$, and oral tetracycline had no effect on glycolytic enzyme activities.

These studies demonstrate that oral folic acid which is neither a substrate nor a coenzyme of these enzymes, increases human jejunal glycolytic enzyme activity in a specific fashion. This would appear to be an action of oral folic acid which has not been recognized previously.

\section{INTRODUCTION}

Human jejunal disaccharidase and glycolytic enzyme activities are regulated by dietary sugars $(1,2)$. Specifically, dietary sucrose or fructose, as compared with glucose, raise sucrase and maltase activities, while lac-

This work was presented in part at the Midwestern Section meeting of The American Federation for Clinical Research, Chicago, Ill., 2 November 1968.

Dr. Rosensweig's present address is Department of Medicine, St. Luke's Hospital Center, New York 10025.

Received for publication 5 March 1969. tase activity is unchanged. In addition, high glucose diets increase jejunal glucokinase and hexokinase activities while high fructose diets increase fructokinase and fructose-1-phosphate aldolase activities.

During the study of one patient with tropical sprue, it was found that his jejunal glycolytic enzymes responded poorly to diet. In view of the well-established effect of folic acid in the treatment of tropical sprue, it seemed appropriate to investigate the effect of folic acid on these enzymes in health and disease. In the present study, we report the effect of oral folic acid on the jejunal glycolytic enzyme activities of normal subjects and fasting obese patients. Also, the effect of tetracycline was studied because of its presently accepted use as an adjunct to folic acid therapy in tropical sprue. A preliminary report of part of this material has appeared (3).

\section{METHODS}

Subjects. Three normal male Caucasian volunteers, ${ }^{1}$ ranging in age from 19 to $25 \mathrm{yr}$, and five obese patients, one Negro and four Caucasians, ranging in age from 31 to 38 $\mathrm{yr}$, were studied. All studies were conducted on a metabolic ward. Subjects were weighed daily after voiding and before breakfast. The obese patients were studied, before and after fasting and also after that refeeding which followed starvation, for weight reduction. Informed consent was obtained in all instances.

Diets. A constant, part solid, part liquid diet was given to the normal subjects and to the obese patients during refeeding. The diet consisted of $3000 \mathrm{cal}: 50 \%$ as carbohydrate, $30 \%$ as fat, and $20 \%$ as protein. The carbohydrate portion was half fructose and half glucose. The solids were essentially carbohydrate-free foods such as meat and eggs. The

${ }^{1}$ The normal subjects volunteered for the study under the provision of Contract No. DA-49-007-MD-549 between the University of Colorado and the Surgeon General of the U. S. Army as part of the conscientious objector program. The provisions of the contract make it obligatory to obtain informed consent in general for the subjects' services, and specifically for each definitive study, and precludes the in vivo use of any radioactive substance.

2038 The Journal of Clinical Investigation Volume 481969 


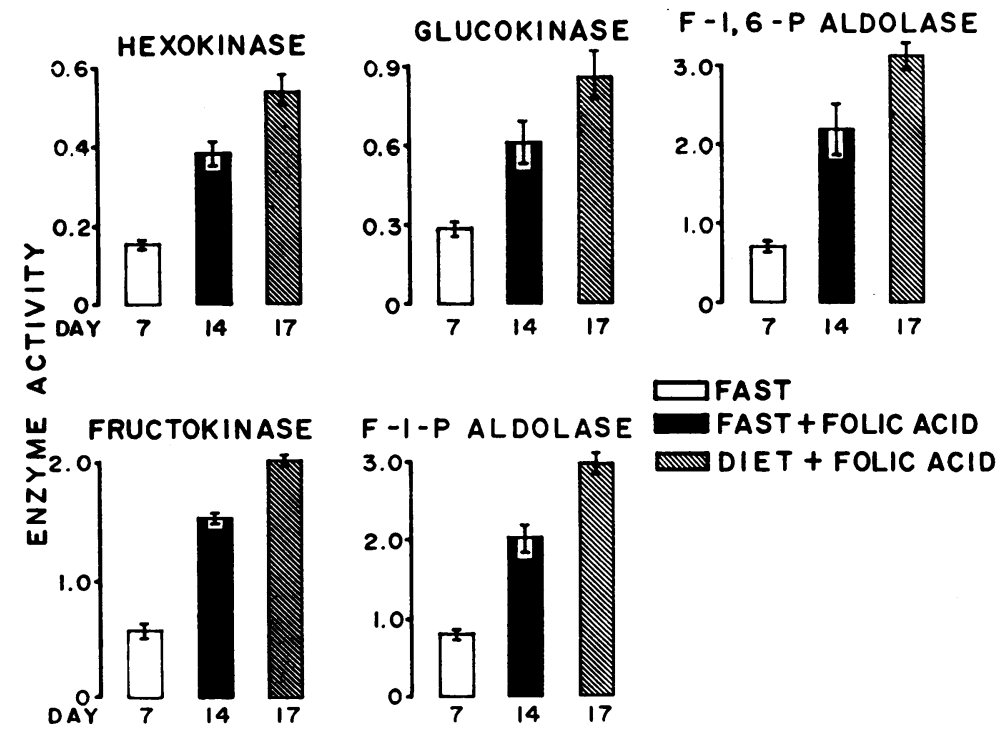

FIGURE 1 Mean glycolytic enzyme activities in five obese patients after 7 days of fasting, 7 days of fasting plus folic acid, and 3 days of refeeding plus folic acid (study I). The SEM is in brackets. F-1,6-P, fructose-1, 6-diphosphate; F-1-P, fructose-1-phosphate.

carbohydrate portion was served as a liquid and custard in which the fat was corn oil and the protein was sodium caseinate. The calculated daily content of folate in the diet was $14 \mu \mathrm{g}$. Except for one subject in study II, all subjects received oral multivitamins daily: ascorbic acid, $300 \mathrm{mg}$; calcium pantothenate, $20 \mathrm{mg}$; cyanocobalamin, $4 \mu \mathrm{g}$; niacinamide $100 \mathrm{mg}$; pyridoxine hydrochloride, $2 \mathrm{mg}$; riboflavin, $10 \mathrm{mg}$; and thiamine mononitrate, $10 \mathrm{mg}$.
Assays. Jejunal biopsies, disaccharidase, and glycolytic enzyme assays were performed as previously described $(1,4)$. The following glycolytic enzymes were assayed: fructokinase, hexokinase, glucokinase, and fructose-1-phosphate and fructose diphosphate aldolases. Activity is expressed as micromoles of product formed per minute per gram wet weight of mucosa. Similar results are obtained when the data are expressed per milligram of protein.

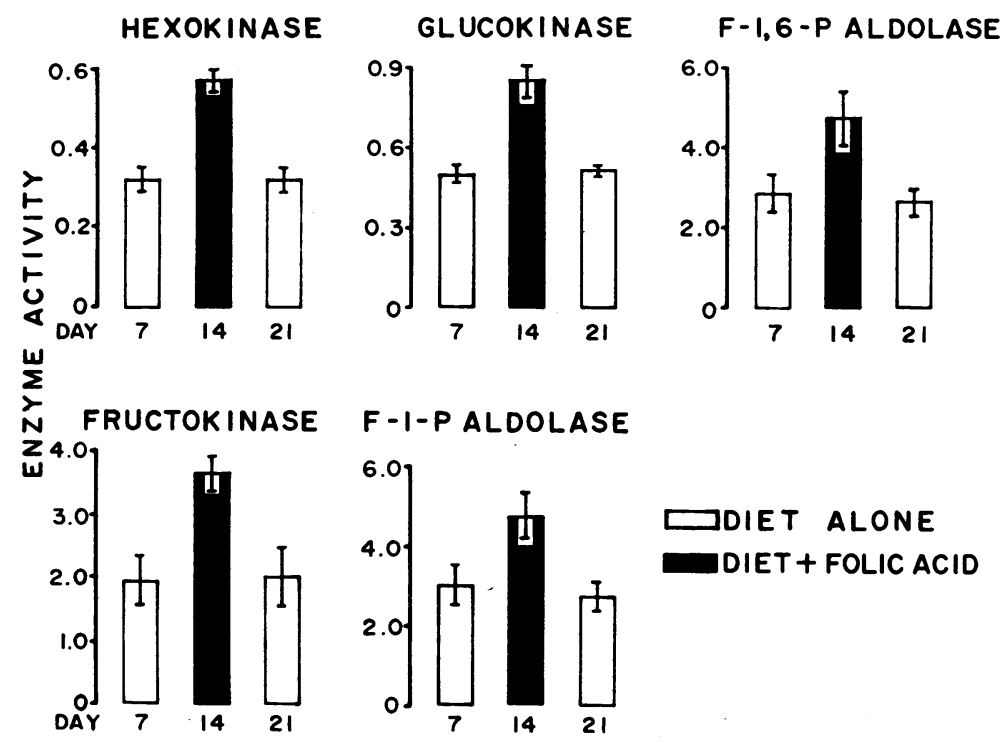

Figure 2 Mean glycolytic enzyme activities in three normal subjects after 7 days of diet alone, 7 days of diet plus folic acid, and 7 days of diet alone (study II). The SEM is in brackets. F-1,6-P, fructose-1, 6-diphosphate; F-1-P, fructose-1-phosphate. 
TABLE I

Effect of Oral Folic Acid Upon Jejunal Fructokinase in Humans

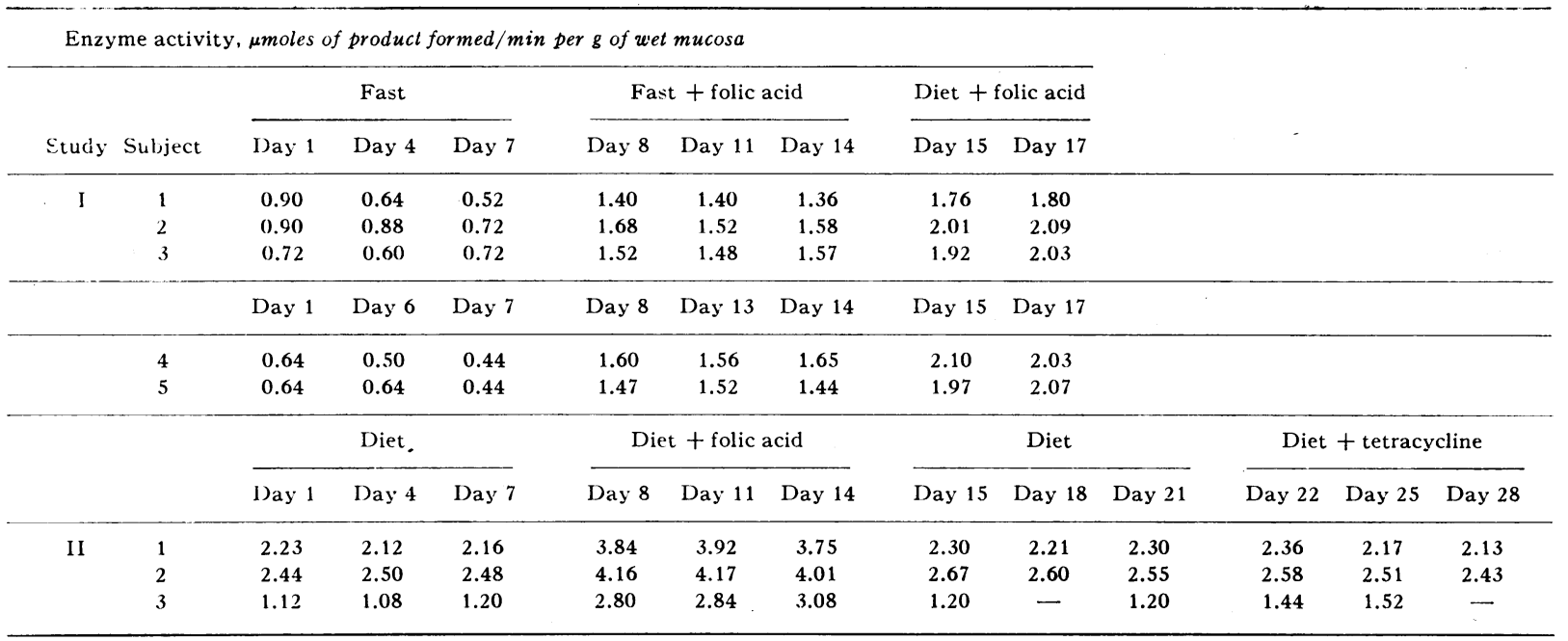

We have used the name glucokinase to designate the high $K_{m}$ hexokinase that we have measured in human and rat intestine $(2,4)$. Other workers have shown that hexokinase types I and II, but not type IV (glucokinase of liver), are present in animal intestine $(5,6)$. Whether this high $K_{m}$ hexokinase in human intestine is the same enzyme as type IV hexokinase of liver is not known. Until the isoenzyme pattern of hexokinases in human intestine is determined, our designation of the high $K_{m}$ hexokinase as glucokinase is considered tentative.

In addition to the measurement of disaccharidase activity, the sucrase to lactase $(\mathrm{S}: \mathrm{L})$ and the maltase to lactase ratios $(M: L)$ were also computed (1).

The addition of doses of folate ranging from $10 \mu \mathrm{g}$ to $1000 \mu \mathrm{g}$ directly to the assay system had no effect on the enzyme activities.

Studies. The investigations were divided into four studies. In study $I$, the five obese patients were fasted for 2 wk and then refed for 3 days. Folic acid, $5 \mathrm{mg}$ by mouth, three times a day, was given during the 2nd wk of fasting and the 3 days of refeeding. Biopsies were performed on days $1,4,7$, $8,11,14,15$, and 17 . Two patients were biopsied on days 6 and 13 instead of 4 and 11.

In study II, the three normal subjects ate a constant 3000 cal diet ( $50 \%$ carbohydrate) for 4 wk. During the 2nd wk only, folic acid, $5 \mathrm{mg}$ by mouth, three times a day, was administered. During the 4th wk only, tetracycline, $250 \mathrm{mg}$ four times a day, was given by mouth. Biopsies were performed on days $1,4,7,8,11,14,15,18,21,22,25$, and 28 .

In study III, two obese patients were fasted for $2 \mathrm{wk}$ and one normal subject was fed a constant diet for 3 wk. For all three, folic acid, $5 \mathrm{mg}$, three times a day, was given intramuscularly during the 2 nd wk only. Biopsies were performed on days $1,4,7,8,11$, and 14 for all three subjects and, also, on days 15,18 , and 21 in the normal subject.

In study IV, one obese patient was fasted for 2 wk and then fed a $1200 \mathrm{cal}$ ( $50 \%$ carbohydrate) diet for 3 days. During the 2nd wk only, vitamin $\mathrm{B}_{12}, 500 \mu \mathrm{g} /$ day, was administered orally in three divided doses. Biopsies were performed on days $1,4,7,8,11,14,15$, and 17 .
Throughout most of the studies serum folate levels were measured before, during, and after folate administration. Serum folate levels were determined by the procedure of Herbert (7) with Lactobacillus casei as the test organism using Difco folic acid media (Difco Laboratories, Detroit, Mich.).

\section{RESULTS}

Oral folic acid treatment produced similar results in both the fasting patients and the normal subjects. The effect of oral folate administration on jejunal glycolytic enzyme activities in studies I and II is presented in Figs. 1 and 2. Table I presents all the individual fructokinase values in studies I and II. Completely analogous data were obtained for the other four enzymes. ${ }^{2}$ There was a significant rise in the activities of all enzymes when oral folic acid was added to the regimen. In the obese patients, there was a further significant rise when diet was added. In the normal subjects, all enzyme activity returned to control values when the folate was discontinued.

The time response to oral folate and the effect of oral tetracycline administration on jejunal hexokinase activity in study II are presented in Fig. 3. The rise in enzyme activity when folate was added to the regimen was complete in 1 day as was the fall back to control values when it was discontinued. Tetracycline had no discernible effect. Identical results were obtained for the other four enzymes. In study I the effect of oral folate

\footnotetext{
${ }^{2}$ Complete data for all five enzymes will be supplied with reprints. Also, this data may be obtained from the National Auxiliary Publications Service of the American Society for Information Science, c/o CCM Information Sciences, Inc., 22 West 34th St., New York City 10001.
} 


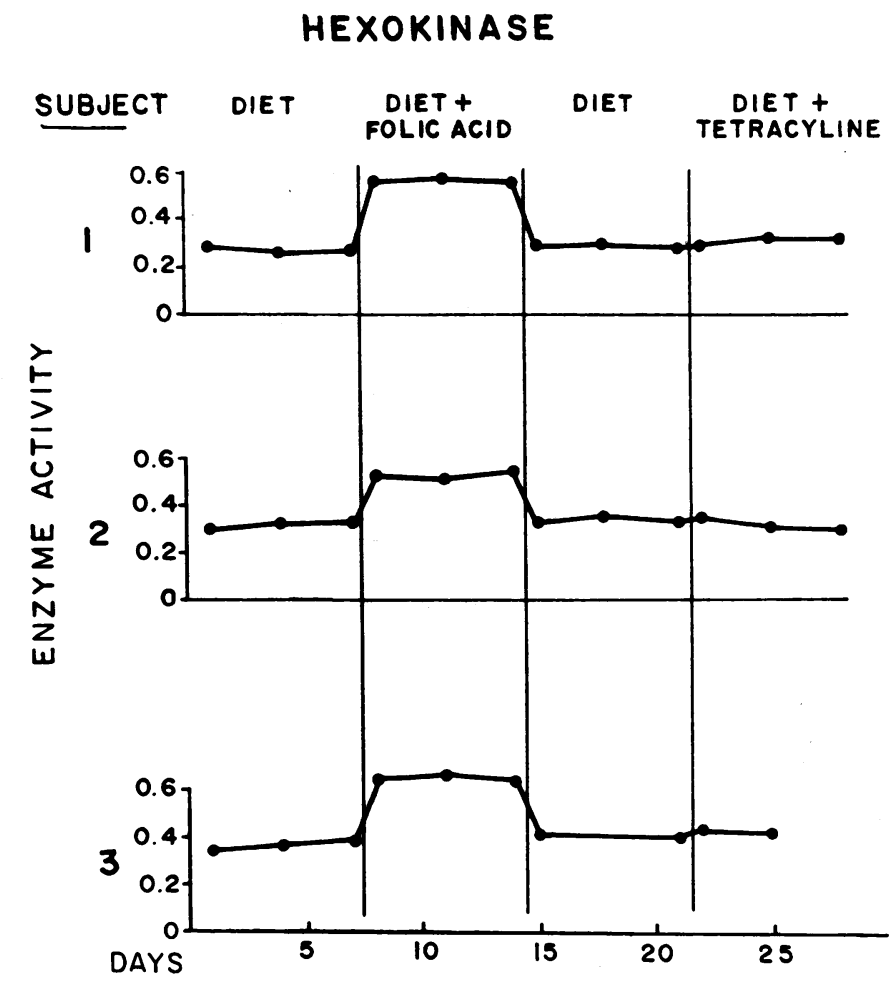

Figure 3 The effect of diet, diet plus folic acid, and diet plus tetracycline on hexokinase activity in three normal subjects (study II).

and diet was complete in 1 day also (Fig. 4). The subject who received no multivitamins had identical results as those who received them.

Effect of intramuscular folate and oral vitamin $B_{\text {is. }}$ In studies III and IV, intramuscular folate and oral vitamin $B_{12}$ had no effect on glucokinase activity in one fasting obese patient (Fig. 5). There was no effect on the other enzymes. Similar results, not shown here, were obtained in the other obese patient and the normal subject on a constant diet.

Effect of folate on disaccharidases. Oral and intramuscular folate, vitamin $\mathrm{B}_{12}$, and tetracycline all failed to alter disaccharidase activity and the $\mathrm{S}: \mathrm{L}$ and $\mathrm{M}: \mathrm{L}$ ratios in any of the obese patients and normal subjects (Fig. 6).

Effect of serum folate. The level of jejunal glycolytic enzyme activity appears to be independent of the serum folate levels. In all instances, serum folate levels rose markedly with the institution of oral folate and remained high even though oral folate was discontinued. However, jejunal glycolytic enzyme activity fell abruptly 1 day after oral folate was discontinued (Fig. 7 ). The serum folate rose markedly after intramuscular administration without any change in jejunal enzyme activity.

\section{DISCUSSION}

These studies demonstrate that oral folic acid is capable of increasing significantly glycolytic enzyme activity in the human jejunum. This is true when folic acid is administered orally both to fasting obese patients and normal subjects on a constant diet. In contrast, intramuscular folic acid, oral tetracycline, and oral vitamin $B_{12}$ have no effect on these enzymes. These results, which could not have been predicted from our present knowledge of folic acid and jejunal enzyme metabolism, suggest that folic acid plays a fundamental role in the regulation of jejunal glycolytic enzyme activity in man. This role of folate has not been recognized previously.

These investigations were a direct outgrowth of our earlier studies demonstrating that dietary sugars can regulate jejunal disaccharidase and glycolytic enzyme activity $(1,2)$. The results with folic acid differ from the previous studies with dietary sugars in that folic acid increased all the glycolytic enzymes studied, whereas the dietary sugars increased primarily those enzymes concerned with the metabolism of that sugar, i.e., glucose increased hexokinase and glucokinase activities while fructose increased fructokinase and fructose-1phosphate aldolase activities. Further, folic acid increases 


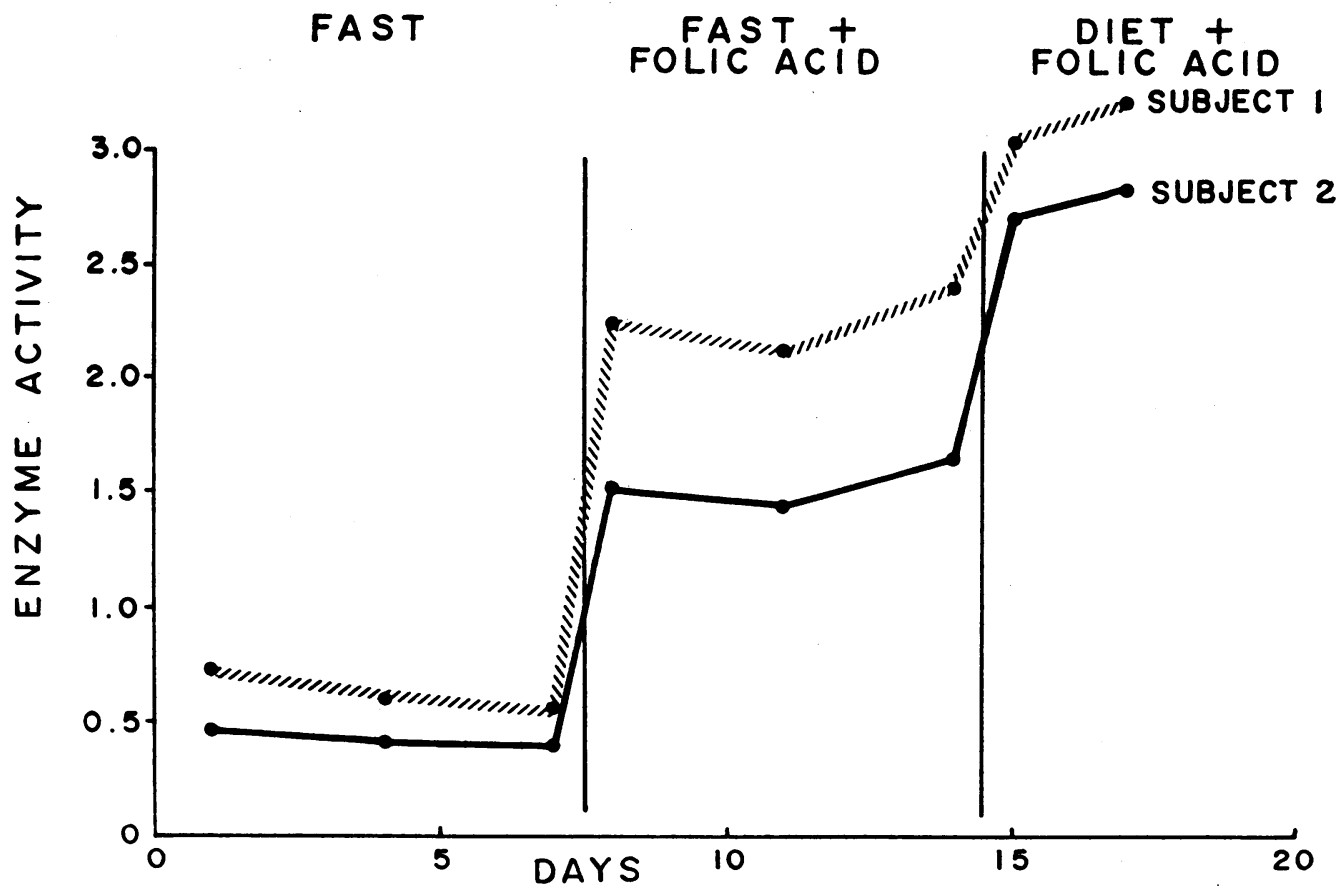

FIGURE 4 The effect of fasting, fasting plus folic acid, and refeeding on fructose-1-phosphate aldolase activity in two representative obese subjects (study I).

all the glycolytic enzymes studied even in the fasting state.

The data demonstrate clearly that oral folic acid, as compared with intramuscular folic acid, is necessary for this effect on jejunal enzyme activity. Possibly, serum folate may not be in the proper metabolic form to increase enzyme activity, or if it is in the active form, it may not be able to enter the intestinal cell from the blood and submucosal side of the cell. Folate may only enter the cell from the luminal side.

\section{GLUCOKINASE}
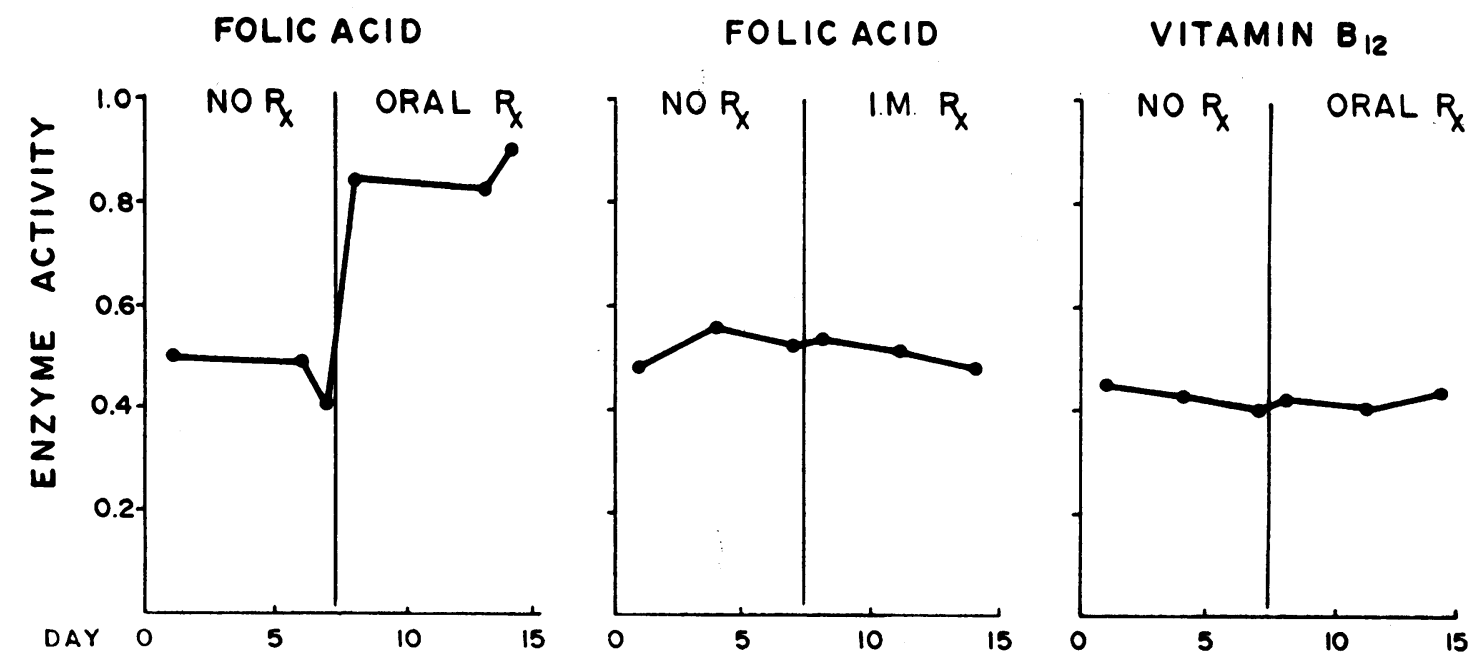

Figure 5 The effect of oral folic acid, intramuscular (I.M.) folic acid, and oral vitamin $B_{12}$ on glucokinase activity in one obese subject (studies III and IV). R, therapy. 
LACTASE

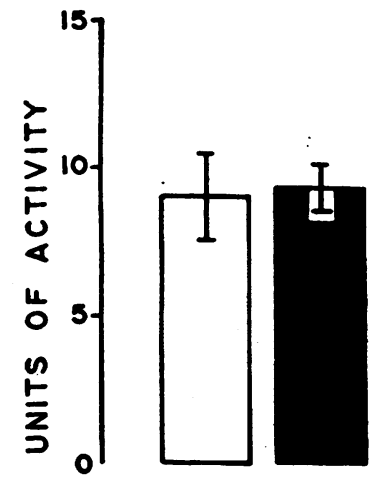

SUCRASE

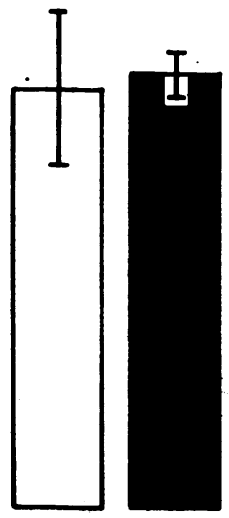

S:L RATIO

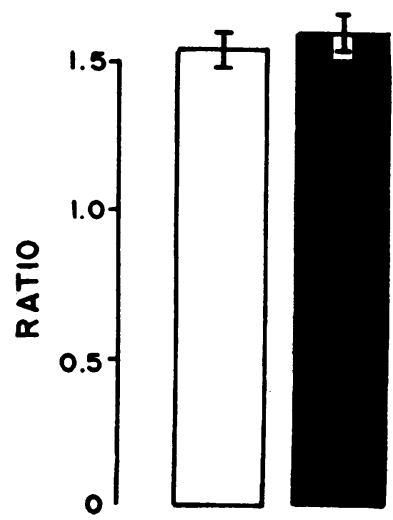

Figure 6 The effect of oral folic acid on mean sucrase and lactase activities and the mean sucrase to lactase. (S/L) ratios in one normal subject (study II). The brackets represent the SEM.

The fact that folic acid increases glycolytic enzyme activity but not disaccharidase activity lends further support to the postulate that there are at least two types of adaptive responses in the human jejunum $(8,9)$. The regulation of glycolytic enzyme activity by dietary sugars is complete in 1 day or less and appears to be mediated through the villus epithelial cell directly $(8,9)$. On the other hand, the regulation of disaccharidase activity by dietary sugars takes 2-5 days and appears to be mediated through the crypt cell and subsequent epithelial cell turnover (10). It is suggested that one response is characteristic of brush border enzymes (disaccharidases) and the other characteristic of cytoplasmic enzymes (glycolytic enzymes). This concept of two different adaptive responses in the human jejunum is strengthened by the fact that folic acid does not alter disaccharidase activity (even after 7 days) but does increase glycolytic enzyme activity in 1 day or less.

The mechanism of this folate-induced increase in glycolytic activity is not known at present. It is not known whether this increase due to folate represents induction of enzyme via new proiein synthesis or is due to enzyme

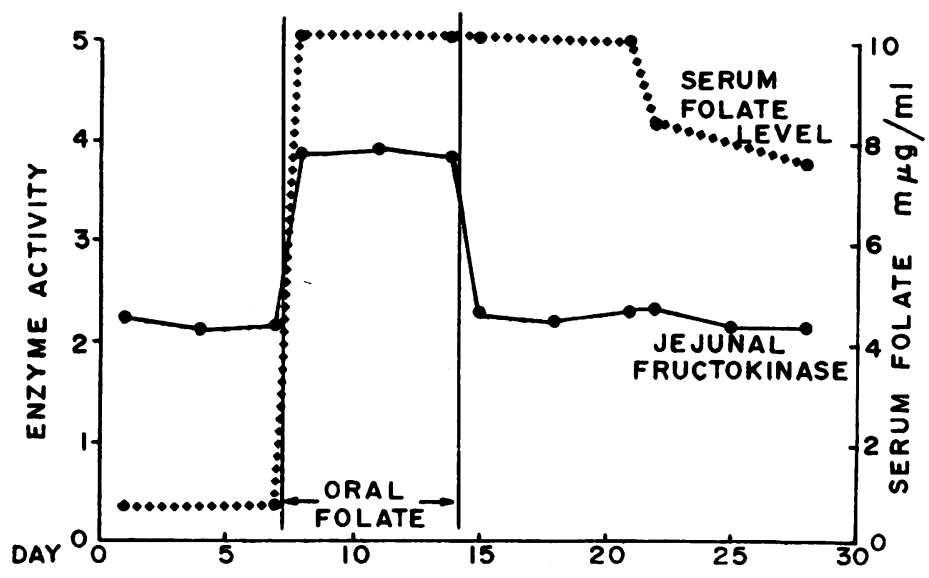

FIGURE 7 The comparison of serum folate level and jejunal enzyme activity in one normal subject (study II). Serum folate levels represented as $10 \mathrm{~m} \mu \mathrm{g} / \mathrm{ml}$ are actually 10 or greater than $10 \mathrm{~m} \mu \mathrm{g} / \mathrm{ml}$. 
activation via allosteric or coenzyme effects. However, regardless of mechanism, the principle of oral folate regulation of jejunal glycolytic enzyme activity is clearly established.

The effect of folic acid is different from the earlier studies $(1,2)$ showing substrate and/or end productinduced increases in enzyme activity. Folic acid is not obviously metabolically related to the enzymes that it increases and, in addition, its effect is quite general. Therefore, to explain its action, it is necessary to invoke another mechanism other than substrate-induced increases in activity.

Folic acid is metabolized to a number of cofactors which are involved in a variety of reactions including the interconversion of serine and glycine, the donation of methyl groups to form methionine and thymidine, the formation of purines, and the formylation of methionyltRNA $(11,12)$. In light of these pathways, the action of folic acid might be mediated through the formation of guanosine triphosphate (GTP) or through $N$-formylmethionyl-tRNA. In microorganisms, GTP is an important initiation factor for protein synthesis and polypeptide chain elongation and $N$-formylmethionyl-tRNA is necessary for the initiation of protein synthesis (12, 13). There are some data to support the involvement of $N$-formylmethionyl-tRNA in mammalian systems, though this has not been conclusively proven $(14,15)$. Our working hypothesis is that folic acid is metabolized to $\mathrm{N}^{10}$-formyltetrahydrofolic acid which formylates methionyl-tRNA to produce $N$-formylmethionyl-tRNA. This is discussed in detail elsewhere $(12,16)$. There may be, of course, other mechanisms whereby folic acid increases glycolytic enzyme activity, but at the moment, these mechanisms are not readily apparent.

The folate effect does not apply to all types of enzyme systems. For example, disaccharidases, which are membrane-bound enzymes, are not affected. This failure of folic acid to alter disaccharidase activity would rule out an increase in the rate of cell division in the crypts as an explanation for the folate effect. Since the effect of folate is demonstrable within $30 \mathrm{~min}$ (17), this implies that the effect of folic acid is directly on the jejunal epithelial cell.

The metabolic significance of folate-mediated increases in jejunal glycolytic enzyme activity is not established. That the folate effect may have physiologic importance is suggested by the fact that doses as low as $100 \mu \mathrm{g}$, which is lower than the average daily dietary intake, are effective in increasing glycolytic enzyme activity (17). If it could be shown that an interruption of folate metabolism interferred with the folate regulation of glycolytic activity, this would support further the concept that folate has a physiologic function in regulating glycolytic enzyme activity.
Recently, we have studied a patient with adult formiminotransferase (FIT) deficiency (18). This patient was malnourished, underweight, had diarrhea, intermittent muscle spasms, and a normal jejunal biopsy. $24 \mathrm{hr}$ urinary formiminoglutamic acid (FIGLU) was markedly elevated, serum folate was elevated, and she had subtle megaloblastic changes in her bone marrow. Large quantities of dietary sugars evoked typical symptoms. The activities of her jejunal glycolytic enzymes were low and there was little or no adaptive response of these enzymes to dietary sugars and oral folic acid.

The fact that this patient's jejunal glycolytic enzyme activity was low and responded poorly, if at all, to dietary sugars and oral folic acid suggests that folate metabolism must take place beyond the FIT step, possibly to $\mathbf{N}^{10}$-formyltetrahydrofolate, in order for the folate effect to occur. These results are consistent with, but do not prove, the hypothesis that folic acid acts to increase certain types of protein synthesis.

In other preliminary studies in patients with tropical sprue (19), it has been shown that jejunal glycolytic enzyme activity is very low and the adaptive response to dietary sugars is markedly impaired. Glycolytic enzyme activity and the adaptive response returns to normal with folate therapy.

We believe, therefore, that the regulation of jejunal glycolytic enzyme activity by oral folic acid is metabolically important and that interference with this regulation leads to clinically significant disease.

One might predict, then, that other patients will be discovered who have gastrointestinal symptoms related to a failure of adaptation of jejunal glycolytc enzymes to dietary sugars and/or folic acid.

\section{ACKNOWLEDGMENTS}

We gratefully acknowledge the assistance of Major C. Miller and her staff for preparation of the diets; Major P. Forney and her staff for nursing assistance; Sergeants A. Padilla and R. Scheussler for help in performing the biopsies; $\mathrm{Mr}$ Carl Gordon for illustrations and Miss L. Carlson for secretarial aid.

The volunteer subjects were provided through the cooperation of Dr. Norman F. Witt, Professor of Chemistry, University of Colorado, and the Surgeon General, U. S. Army (Contract No. DA-49-007-MD-549).

\section{REFERENCES}

1. Rosensweig, N. S., and R. H. Herman. 1968. The control of jejunal sucrase and maltase activity by dietary sucrose or fructose in man: a model for the study of enzyme regulation in man. J. Clin. Invest. 47: 2253.

2. Rosensweig, N. S., F. B. Stifel, R. H. Herman, and D. Zakim. 1968. Dietary regulation of the glycolytic enzymes. II. Adaptive changes in human jejunum. Biochim. Biophys. Acta. 170: 228.

3. Rosensweig, N. S., F. B. Stifel, Y. F. Herman, and R. H. Herman. 1968. Regulation of human jejunal 
glycolytic enzymes by oral folic acid. Clin. Res. 16: 450 . (Abstr.)

4. Stifel, F. B., N. S. Rosensweig, D. Zakim, and R. H. Herman. 1968. Dietary regulation of the glycolytic enzymes. I. Adaptive changes in rat jejunum. Biochim. Biophys. Acta. 170: 221.

5. Katzen, H. M., and R. T. Schimke. 1965. Multiple forms of hexokinase in the rat:.Tissue distribution, age dependency and properties. Proc. Nat. Acad. Sci. U.S.A. 54: 1218.

6. Srivastava, L. M., P. Shakespeare, and G. Hübscher. 1968. Glucose metabolism in the mucosa of the small intestine: A study of hexokinase activity. Biochem. J. 109: 35 .

7. Herbert, V. 1966. The aseptic addition method for Lactobacillus casei assay of folate activity in human serum. J. Clin. Path. (London). 19: 12.

8. Rosensweig, N. S., F. B. Stifel, R. H. Herman, and D. Zakim. 1969. Time response of diet-induced changes in human jejunal glycolytic enzymes. Fed. Proc. 28: 323. (Abstr.)

9. Rosensweig, N. S., F. B. Stifel, D. Zakim, and R. H. Herman. 1969. Time response of human jejunal glycolytic enzymes to a high sucrose diet. Gastroenterology. 57: 143.

10. Rosensweig, N. S., and R. H. Herman. 1969. Time response of jejunal sucrase and maltase activity to a high sucrose diet in normal man. Gastroenterology. 56: 500.

11. Stokstad, E. L. R., and J. Koch. 1967. Folic acid metabolism. Physiol. Rev. 47: 83.

12. Ochoa, S. 1968. Translation of the genetic message. Naturwissenschaften. 55: 505.

13. Lipmann, F. 1969. Polypeptide chain elongation in protein biosynthesis. Science (Washington). 164: 1024.

14. Noll, H. 1966. Chain initiation and control of protein synthesis. Science (Washington). 151: 1241.

15. Caskey, C. T., B. Redfield, and H. Weissbach. 1967. Formylation of guinea pig liver methionyl-sRNA. Arch. Biochem. Biophys. 120: 119.

16. Herman, R. H., and N. S. Rosensweig. 1969. The initiation of protein synthesis. Amer. J. Clin. Nutr. 22: 806.

17. Rosensweig, N. S., F. B. Stifel, Y. F. Herman, and R. H. Herman. 1969. Regulation of human jejunal glycolytic enzymes by oral folic acid: Time and dose response. Amer. J. Clin. Nutr. 22: 677. (Abstr.)

18. Herman, R. H., N. S. Rosensweig, F. B. Stifel, and Y. F. Herman. 1969. Adult formiminotransferase deficiency: A new entity. Clin. Res. 17: 304.

19. Rosensweig, N. S., R. H. Herman, F. B. Stifel, Y. F. Herman, A. Dreskin, and D. Chipman. 1969. Effect of folic acid on jejunal glycolytic enzyme activity in tropical sprue. Gastroenterology. 56: 1261. (Abstr.) 